\title{
Determination of storage volume required in a sub-surface stormwater detention/retention system
}

\begin{abstract}
A new sub-surface detention/retention system, called the Storage-Infiltration Block (SIB) system, has been developed for the purposes of reduction of volume and flow rate of stormwater runoff and recharging groundwater. This paper presents a method in the determination of the maximum storage volume and maximum surface area required for the system. The method is based on the determination of the maximum difference between the volume of stormwater runoff entering the system and the volume released from the system by the infiltration process. The stormwater runoff inflow volume is determined using the Rational formula. The rainfall intensities were calculated based on the rainfall IDF relationships published by the Department of Irrigation and Drainage, Malaysia. An example is also included in this paper to demonstrate the calculation procedure. The example shows that the prediction of the maximum storage volume using this method is fast and accurate.
\end{abstract}

Faculty or Institute: Faculty of Engineering 